\title{
Heat Transfer Modeling for Rigid High-Temperature Fibrous Insulation
}

\author{
Kamran Daryabeigi * \\ NASA Langley Research Center, Hampton, Virginia, 23681 \\ George R. Cunnington ${ }^{\dagger}$ \\ Cunnington and Associates, Palo Alto, California, 94303 \\ and \\ Jeffrey R. Knutson* \\ NASA Langley Research Center, Hampton, Virginia, 23681
}

\begin{abstract}
Combined radiation and conduction heat transfer through a high-temperature, highporosity, rigid multiple-fiber fibrous insulation was modeled using a thermal model previously used to model heat transfer in flexible single-fiber fibrous insulation. The rigid insulation studied was alumina enhanced thermal barrier (AETB) at densities between 130 and $260 \mathrm{~kg} / \mathrm{m}^{3}$. The model consists of using the diffusion approximation for radiation heat transfer, a semi-empirical solid conduction model, and a standard gas conduction model. The relevant parameters needed for the heat transfer model were estimated from steadystate thermal measurements in nitrogen gas at various temperatures and environmental pressures. The heat transfer modeling methodology was evaluated by comparison with standard thermal conductivity measurements, and steady-state thermal measurements in helium and carbon dioxide gases. The heat transfer model is applicable over the temperature range of 300 to $1360 \mathrm{~K}$, pressure range of 0.133 to $101.3 \times 10^{3} \mathrm{~Pa}$, and over the insulation density range of 130 to $260 \mathrm{~kg} / \mathrm{m}^{3}$ in various gaseous environments.
\end{abstract}

\section{Nomenclature}

$=$ constant exponent for solid conduction model

$=$ specific heat, $\mathrm{J} / \mathrm{kg} / \mathrm{K}$

$=$ fiber diameter, $\mathrm{m}$

$=$ gas collision diameter, $\mathrm{m}$

$=$ specific extinction coefficient, $\mathrm{m}^{2} / \mathrm{kg}$

$=$ constant parameter for solid conduction model

$=$ fiber volume solid fraction ratio

$=$ Boltzmann constant, $1.3806 \times 10^{-23} \mathrm{~J} / \mathrm{K}$

$=$ thermal conductivity, $\mathrm{W} / \mathrm{m} / \mathrm{K}$

$=$ gas thermal conductivity at atmospheric pressure, $\mathrm{W} / \mathrm{m} / \mathrm{K}$

$=$ thermal conductivity of bulk fiber material. $\mathrm{W} / \mathrm{m} / \mathrm{K}$

$=$ insulation thickness, $\mathrm{m}$

$=$ gas conduction characteristic length, $\mathrm{m}$

$=$ effective index of refraction

$=$ pressure, $\mathrm{Pa}$

$=$ Prandtl number

$=$ heat flux, $\mathrm{W} / \mathrm{m}^{2}$

$=$ temperature, $\mathrm{K}$

\footnotetext{
* Aerospace Engineer, Structural Mechanics and Concepts Branch, Mail Stop 190. Senior Member, AIAA.

${ }^{\dagger}$ President, Cunnington and Associates. Associate Fellow, AIAA.

*Electrical Engineering Technician, Systems Integration and Test Branch, Mail Stop 424.
} 

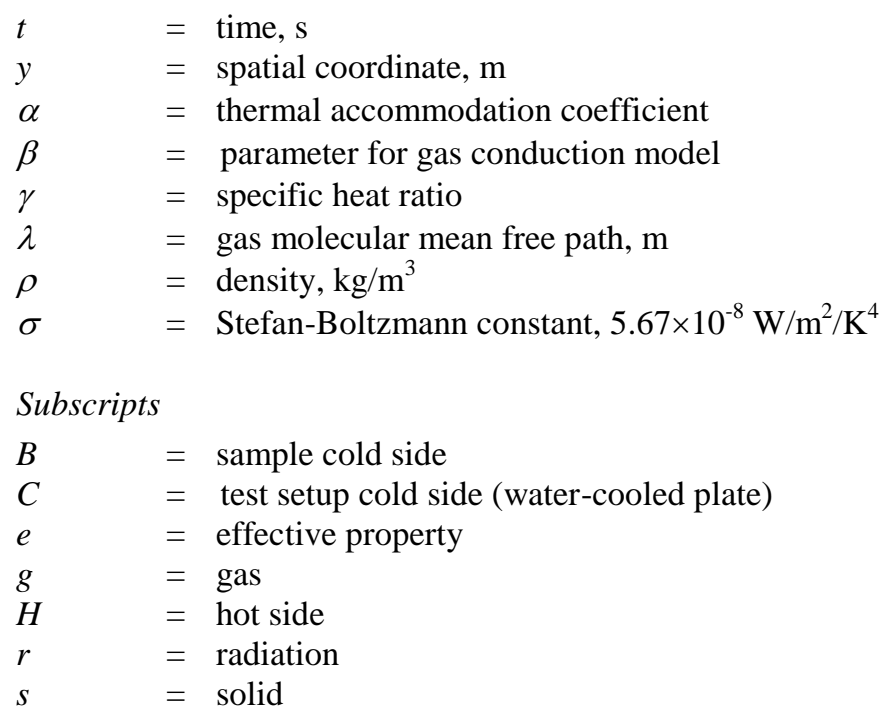

\section{Introduction}

$\mathrm{H}$ eat transfer through fibrous insulation has been the subject of great interest in the aerospace community because of the use of high-porosity fibrous insulation in thermal protection systems (TPS). Heat transfer in fibrous insulation consists of conduction (both solid and gaseous) and radiation. Significant work has been devoted to developing radiation heat transfer modeling with various degrees of complexity for flexible and rigid fibrous insulation with single-fiber compositions. The simplest approach has been to use radiation conductivity in terms of a Rosseland mean coefficient based on the diffusion approximation. ${ }^{1,2}$ A more complex approach uses a rigorous formulation for the two-dimensional scattering characteristics of fibers, with the resulting radiation model using deterministic parameters that define the composition and morphology of the medium, which include: distributions of fiber size and orientation, fiber volume fraction, and the spectral complex refractive index of the fibers. ${ }^{3,4}$ This radiation model is limited to the independent scattering regime, requiring detailed knowledge of fiber orientation with respect to the boundaries, and accurate spectral complex refractive index data. Up to the present, this radiation formulation combined with conduction heat transfer has only been successfully developed and validated for a silica fiber rigid insulation and a soda-lime glass flexible fiber insulation. ${ }^{5}$

Newer rigid fibrous insulation systems have multiplefiber compositions for mechanical and thermal stability at higher temperatures. The alumina enhanced thermal barrier (AETB) insulation studied here is a rigid fibrous insulation with a nominal composition of $68 \%$ silica, $20 \%$ alumina, and $12 \%$ aluminoborosilicate fibers, with different fiber lengths and fiber size distributions for each fiber. A scanning electron micrograph (SEM) of this insulation is shown in Fig. 1, which shows the different fibers with their fiber size distributions and orientations. Application of the more complex radiation models to a multiple-fiber composition with varying fiber size distributions and orientations is extremely formidable. Therefore, the simpler diffusion approximation for radiation heat transfer was used in this study. Previously, a much simpler modeling approach had been used for AETB, which used a third order

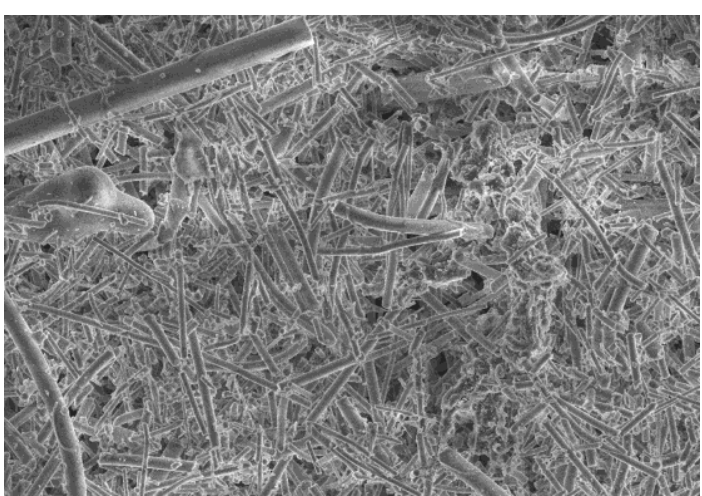

Fig. 1 Scanning electron micrograph of AETB at a magnification factor of $\mathbf{5 0 0}$. polynomial variation of thermal conductivity due to combined radiation and solid conduction with temperature, with the polynomial coefficients estimated from thermal measurements in a vacuum. ${ }^{6}$ The shortcoming of the previous technique is that it did not model radiation and solid conduction separately, and different polynomial fits had to be developed for different sample densities. In the modeling presented here each mode of heat transfer is modeled separately. The model uses the diffusion approximation for radiation; a semi-empirical solid conduction model $;, 7$ and a gas conduction model based on the 
temperature jump theory. ${ }^{8}$ The same modeling approach had previously been successfully applied to various singlefiber flexible fibrous insulation samples. ${ }^{9}$ The advantage of the improved modeling presented here is that it provides insight into the significance of various modes of heat transfer at various temperatures and pressures. Furthermore, the model is applicable in any gaseous environment and for any density of the insulation as long as the fiber properties (index of refraction, size distribution, orientation, length) do not vary with insulation density.

The objective of the present work was to develop a thermal model for a multiple-fiber composition rigid insulation with the relevant parameters estimated from steady state thermal tests. The methodology consisted of estimation of relevant parameters for radiation and solid conduction models from thermal measurements on an AETB sample with a density of $188 \mathrm{~kg} / \mathrm{m}^{3}$ in a vacuum at various temperatures between 300 and $1360 \mathrm{~K}$. The heat transfer model was evaluated by comparison of model predictions with measurements on AETB samples with densities of 134 and $263 \mathrm{~kg} / \mathrm{m}^{3}$ in a vacuum. Then, the relevant gas conduction parameter was determined from thermal measurements on AETB samples with densities of 134 and $188 \mathrm{~kg} / \mathrm{m}^{3}$ at various pressures (13.3 to $101.3 \times$ $10^{3} \mathrm{~Pa}$ ) and temperatures in nitrogen gas. The gas conduction model was evaluated by comparison of model predictions with measurements on an AETB sample with density of $188 \mathrm{~kg} / \mathrm{m}^{3}$ at various pressures and temperatures in argon and carbon dioxide gases. The overall model was finally evaluated by comparing predicted thermal conductivity with standard thermal conductivity measurements ${ }^{10}$ in nitrogen at a commercial thermal property measurement laboratory.

\section{Analytical Approach}

Heat transfer through high-porosity fibrous insulation is composed of combined radiation and conduction heat transfer. Conduction consists of both solid and gaseous conduction. Forced convection in fibrous insulations is insignificant in the absence of sufficient pressure gradient and flow path across the insulation. Natural convection is insignificant in fibrous insulations with densities of $20 \mathrm{~kg} / \mathrm{m}^{3}$ or higher. ${ }^{11,12}$ In the absence of forced or natural convection, the governing one-dimensional conservation of energy equation using the diffusion approximation for radiation heat transfer is

$$
\rho c \frac{\partial T}{\partial t}=\frac{\partial}{\partial y}\left(k \frac{\partial T}{\partial y}\right)
$$

where $k$ is obtained by superposition of the thermal conductivities due to solid conduction, gas conduction, and radiation

$$
k=k_{s}+k_{g}+k_{r}
$$

The formulation for each of the thermal conductivity terms is subsequently discussed.

\section{A. Radiation}

The radiant thermal conductivity is

$$
k_{r}=\frac{16 \pi^{* 2} T^{3}}{3 \rho e}
$$

Specific extinction coefficient, $e$, is an intrinsic property of fibers and is a function of temperature, fiber material, fiber diameter, and fiber orientation. The effective index of refraction, $n^{*}$, of fibrous media is a function of fiber volume fraction, fiber properties, and temperature. ${ }^{13}$ The effective index of refraction of various fibers can be obtained from the index of refraction of these materials based on modeling by Caren, ${ }^{13}$ but estimation of the effective index of a multiple-fiber composition is a formidable task. Therefore, the combined quantity $e / n *^{2}(T)$ was estimated from experimental data in a vacuum at various test temperatures using a genetic algorithm-based parameter estimation technique. ${ }^{14}$

\section{B. Solid Conduction}

An exact theoretical formulation of solid conduction for either a single-fiber or a multiple-fiber fibrous insulation is a formidable task because of the tenuous nature of the myriad of different paths of varying fiber lengths and cross sectional areas. Therefore, the semi-empirical approach ${ }^{5,7}$ that had been previously ${ }^{9}$ used to model solid conduction heat transfer in single-fiber flexible fibrous insulation was used

$$
k_{S}(T)=F_{S} f_{v}^{b} k_{S}^{*}(T)
$$


which relates the solid thermal conductivity of fibrous insulation to the thermal conductivity of bulk fiber material, $k_{s}{ }^{*}$, and fiber volume fraction, $f_{v}$. The fiber volume fraction for this multiple-fiber composition was calculated using the ratio of AETB sample density to the density of bulk material, with the latter determined using the rule of mixtures based on the mass percentages of the three components of AETB. The model assumes that the solid conductivity is independent of fiber diameter and varies with fiber volume fraction raised to a power, $b$, typically between 1 and 3., ${ }^{75}$ The exponent $b$ was assumed to be unity in the present study, because it produced better agreement with experimental results. The parameter $F_{s}$ is a global property that relates the micro-scale geometric effects of fiber matrix with bulk dimensions, and accounts for the various fiber path lengths, fiber arrangement, and fiber to fiber contacts, and is assumed to be temperature independent. $F_{s}$ was estimated simultaneously with $e / n^{*^{2}}$ using experimental data in a vacuum at various test temperatures.

The bulk thermal conductivity, $k_{s}^{*}$, for this multiplefiber fibrous insulation was estimated from bulk thermal conductivity of the three fiber constituents from the literature: alumina, ${ }^{16}$ silica, ${ }^{16}$ and aluminoborosilicate, ${ }^{17}$ by using a series thermal network model based on fiber volume fractions of each constituent. Assumption of a series thermal network for the three fiber materials is an idealization. It assumes that different fibers are randomly oriented in planes perpendicular to the heat flow direction,

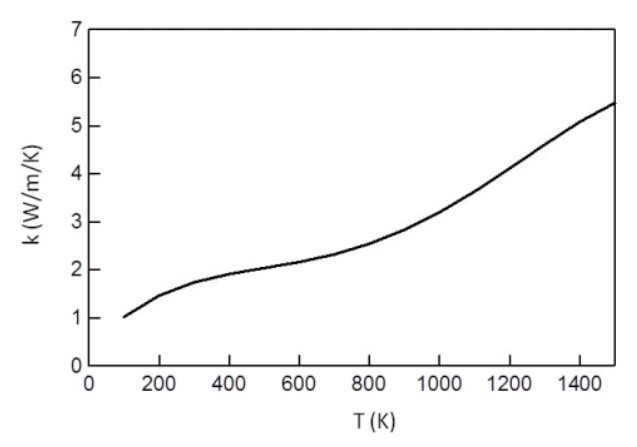

Fig. 2 Estimated thermal conductivity of bulk fiber material for AETB.

while in reality fibers are randomly oriented in space. A fourth order polynomial fit was determined for the bulk thermal conductivity in the temperature range of 100 to $1500 \mathrm{~K}$

$$
k_{S}^{*}(T)=0.3628+8.473 \times 10^{-3} T-1.687 \times 10^{-5} T^{2}+1.58 \times 10^{-8} T^{3}-4.528 \times 10^{-12} T^{4}
$$

The variation of the estimated bulk thermal conductivity with temperature is shown in Fig. 2

\section{Gas Conduction}

The standard gas thermal conductivity variation with pressure based on the temperature jump theory ${ }^{8}$ was used

$$
k_{g}(T, P)=\frac{k_{g 0}(T)}{1+2 \frac{\beta}{\operatorname{Pr}} \frac{\lambda}{L_{C}}}
$$

where $k_{g 0}(T)$ is the thermal conductivity of the gas at atmospheric pressure. The parameter $\beta$ is defined as

$$
\beta=\left(\frac{2-\alpha}{\alpha}\right) \frac{2 \gamma}{(\gamma+1)}
$$

Since there is limited data for thermal accommodation coefficient, $\alpha$, between various gases and fiber materials, a thermal accommodation coefficient of unity was used for all the fibers and gaseous environments considered in the present study. An accommodation coefficient of unity produced better agreement with experimental results for the multiple-fiber rigid insulation in the various gases used in this study, as had been previously demonstrated with various single-fiber flexible fibrous insulation materials. ${ }^{9}$ The gas molecular mean free path is

$$
\lambda=\frac{K_{B} T}{\sqrt{2} \pi d_{m}^{2} P}
$$

Once $k_{g o}(T), \operatorname{Pr}(T), \chi(T)$, and $d_{m}$ are known from literature, ${ }^{18-21}$ the gas conduction contribution in a fibrous insulation can be easily calculated if the gas conduction characteristic length (pore size) is known. The pore size, $L_{c}$, is not easy to define, therefore, an empirical formulation that assumes fibers are randomly oriented in planes perpendicular to the direction of heat flow was used ${ }^{7}$

$$
L_{c}=\frac{\pi}{4} \frac{d_{p}}{f_{v}}
$$

The effective fiber diameter, $d_{p}$, for this multiple-fiber fibrous insulation was estimated using experimental data at various test temperatures and pressures in nitrogen gas. A comparison between experimental measurements of pore diameters and calculated values for fibrous materials is provided by Kaganer. ${ }^{22}$ 
The analytical thermal conductivity in Eq. (2) is obtained by substituting for radiant, solid, and gas thermal conductivity terms from Eqs. (3), (4), and (6), respectively. For transient thermal analysis the only additional information that is needed is the effective volumetric heat capacity of the insulation, which can be obtained from volumetric heat capacities of the fiber materials ${ }^{23}$ and the gas ${ }^{19}$ using the rule of mixtures, or from standard experimental techniques.

\section{Experimental Approach}

Data reported here were generated using the steady-state thermal test setup at NASA Langley Research Center (LaRC) which provides effective thermal conductivity data with large temperature differences maintained across the sample thickness. A limited set of thermal conductivity data was also generated using the transient radiant step heating technique,$^{10}$ with small temperature differences maintained across the sample thickness, for evaluation of the heat transfer model. The test samples and the measurement techniques are briefly described.

\section{A. Test Samples}

Data on AETB samples ${ }^{\S}$ with three different densities were considered: 134 and 188, and $263 \mathrm{~kg} / \mathrm{m}^{3}$ (nominal densities of 8,12 and $16 \mathrm{lb} / \mathrm{ft}^{3}$, respectively). The AETB data in nitrogen with sample densities of 134 and 188 $\mathrm{kg} / \mathrm{m}^{3}$ had been previously reported elsewhere; ${ }^{6}$ while the data on sample density of $263 \mathrm{~kg} / \mathrm{m}^{3}$ in vacuum and data on sample density of $188 \mathrm{~kg} / \mathrm{m}^{3}$ in argon and carbon dioxide gas were generated for this study. AETB has a nominal composition of $68 \%$ silica, $20 \%$ alumina, and $12 \%$ aluminoborosilicate fibers. AETB samples by other manufacturers may contain up to $3 \%$ silicon carbide powder which may result in lower thermal conductivities at higher temperatures compared to the samples studied in the present study, as had previously been observed ${ }^{24}$ on the LI-2200 rigid silica samples with a nominal density of $352 \mathrm{~kg} / \mathrm{m}^{3}\left(22 \mathrm{lb} / \mathrm{ft}^{3}\right)$. All three samples used in this study were $304.8 \times 304.8 \mathrm{~mm}, 25.4 \mathrm{~mm}$ thick.

\section{B. Effective Thermal Conductivity Measurements}

Steady-state effective thermal conductivity data with large temperature differences maintained across the sample thickness were generated in the LaRC steady-state thermal test setup, described in detail elsewhere ${ }^{25,26} \mathrm{~A}$ schematic of the test setup is shown in Fig. 3. The main components are: a quartz lamp radiant heater array, an Inconel septum plate, a water-cooled plate, test sample, and refractory ceramic board insulation. A thin layer (1.6 mm thick) of liquid bismuth alloy was also used between the top of the water-cooled plate and the bottom of the rigid insulation test sample to eliminate thermal contact resistance between the sample and water-cooled plate. ${ }^{26}$ The planar area of the water-cooled and septum plates is $304.8 \times 304.8 \mathrm{~mm}$. The water-cooled plate is equipped with nine flushmounted thin-film heat flux gages that provide simultaneous heat flux and temperature measurements, while the septum plate is instrumented with 23 metal-sheathed thermocouples. Thermal contact resistance between the sample hot side and septum plate was ignored, and it was assumed that the septum plate and sample hot side temperatures were equal. Even though this assumption may not be strictly valid, its use had previously ${ }^{26}$ resulted in thermal conductivity predictions for the LI-900 rigid silica insulation that had matched historical published data. ${ }^{27}$ The cold side of the rigid test samples was instrumented with 3 to 6 flush mounted thin stainless steel foil thermocouples to provide the average sample cold-side temperature.

Data from instrumentation located in the central $127 \times 127 \mathrm{~mm}$ section of the test setup on the water-cooled and septum plates are used for the effective thermal conductivity measurements, while data from instrumentation located outside of the central region are used to assess deviations from one dimensional heat transfer in the setup. The average heat flux and temperature calculated from five heat flux gages located in the central region of the water-cooled plate provide the heat flux, $q^{\prime \prime}$, and the test setup cold-side temperature, $T_{C}$, while the average temperature calculated from 13 thermocouples located in the central region of the septum plate provides the hot side temperature, $T_{H}$. The average sample cold-side temperature, $T_{B}$, is calculated from the 3 to 6 flush mounted thin foil thermocouples on the sample cold-side surface. Because of the use of the liquid

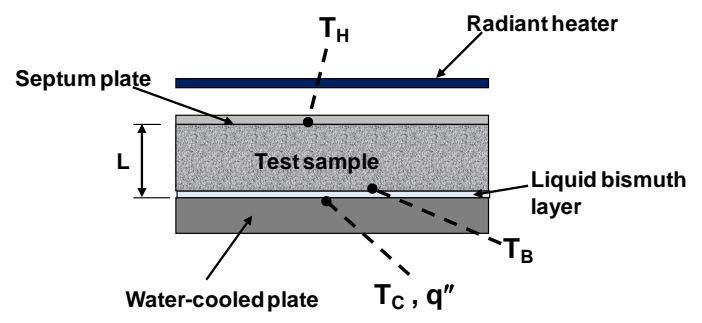

Fig. 3 Schematic of steady-state test setup.

\footnotetext{
${ }^{\S}$ Forrest Machining Inc
} 
bismuth layer the difference between $T_{B}$ and $T_{C}$ for all the data presented here varied between 0.3 and $15.5 \mathrm{~K}$ with an average of $3.8 \mathrm{~K}$; nevertheless, $T_{B}$ is used in the calculations for completeness. The effective thermal conductivity is then calculated from

$$
k_{e}=\frac{q^{\prime \prime} L}{\left(T_{H}-T_{B}\right)}
$$

For an optically thick insulation, the effective thermal conductivity is related to thermal conductivity through

$$
k_{e}\left(T_{H}, T_{B}, P\right)=\frac{1}{T_{H}-T_{B}} \int_{T_{B}}^{T_{H}} k(T, P) d T
$$

Tests were conducted with various $T_{H}$ between 530 and $1360 \mathrm{~K}$, with $T_{C}$ maintained around $330 \mathrm{~K}$. At each $T_{H}$ set point, tests were conducted at various static pressures between 0.133 and $101.3 \times 10^{3} \mathrm{~Pa}$ in either nitrogen, argon, or carbon dioxide gas. Uncertainty estimates were calculated for each measurement and for each quantity calculated from measured data $\left(T_{H}, T_{C}, T_{B}, q^{\prime \prime}\right.$, and $\left.k_{e}\right)$ using standard uncertainty analysis. ${ }^{28}$ The overall uncertainty consisted of the contributions of random and bias uncertainties for each quantity, and uncertainties due to spatial nonuniformity of spatially-averaged quantities. All test results are presented with the relevant uncertainty ranges.

\section{Thermal Conductivity Measurements}

Previously reported ${ }^{6}$ standard thermal conductivity data measured on AETB samples with densities of 134 and $194 \mathrm{~kg} / \mathrm{m}^{3}$ in nitrogen gas were used to evaluate the heat transfer model developed in the present study. These measurements had been conducted at a thermophysical property measurement laboratory using the transient radiant step heating technique referred to as the "three point method", described in detail elsewhere. ${ }^{10}$ This measurement technique provides thermal conductivity data with nominal temperature differences of $10 \mathrm{~K}$ across the test sample thickness with a reported measurement uncertainty of $\pm 10 \%$, as opposed to measurements at LaRC which provide effective thermal conductivity data with large temperature differences (200 to $1000 \mathrm{~K}$ ) across the sample thickness.

\section{Discussion of Results}

For all the results presented here, the effective thermal conductivity predictions and measurements, $k_{e}\left(T_{H}, T_{B}, P\right)$, are plotted versus $T_{H}$ at various pressures. The average $T_{B}$ for experimental data in each figure is provided. The thermal conductivity predictions and measurements, $k(T, P)$, are plotted versus $T$ at various pressures. The effective thermal conductivity measurements in a vacuum at various temperatures were used to estimate the relevant parameters for radiation and solid conduction, $e / n *^{2}(T)$ and $F_{s}$. The effective thermal conductivity measurements at higher pressures in nitrogen at various temperatures were used to estimate the relevant parameter for gas conduction, $d_{p}$.

The low-pressure $(0.133 \mathrm{~Pa})$ experimental effective thermal conductivity data as a function of $T_{H}$ for the three sample densities is shown in Fig. 4. The symbols represent the measured data and the error bars represent the experimental uncertainties obtained from detailed uncertainty analysis for each data point. Average $T_{B}$ for these measurements at $0.133 \mathrm{~Pa}$ was $335 \pm 10.1 \mathrm{~K}$. The variation of effective thermal conductivity data with temperature and density shown in the figure follows first principles. At this low pressure the only modes of heat transfer are radiation and solid conduction. At lower temperatures, $T_{H}<1000 \mathrm{~K}$, solid conduction is the dominant mode of heat transfer and since it is directly proportional to density, effective thermal conductivity increases with increasing insulation density. At

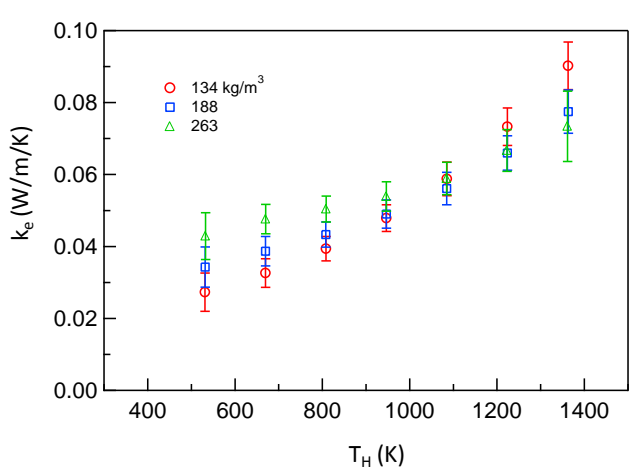

Fig. 4 Measured effective thermal conductivity of AETB as a function of $T_{H}$ at $0.133 \mathrm{~Pa}$ at three sample densities $\left(T_{B}=335 \pm 10.1 \mathrm{~K}\right)$.

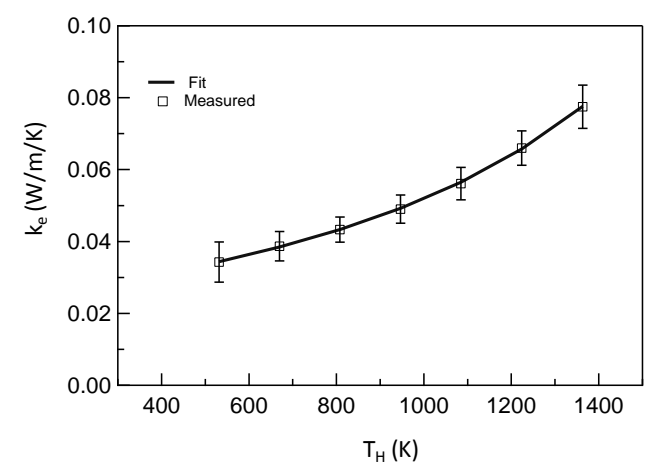

Fig. 5 Fit of effective thermal conductivity of AETB as a function of $T_{H}$ at $0.133 \mathrm{~Pa}$ for sample density of $188 \mathrm{~kg} / \mathrm{m}^{3}$. 
higher temperatures, radiation is the dominant mode of heat transfer and since it is inversely proportional to density, effective thermal conductivity decreases with increasing density. The effective thermal conductivity data for the sample with density of $188 \mathrm{~kg} / \mathrm{m}^{3}$ was used to simultaneously estimate the relevant radiation and solid conduction parameters: $e / n^{2}(T)$ and $F_{s}$. A third order polynomial was used to model variation of $e / n *^{2}$ with temperature. The parameter estimation was accomplished by minimizing the sum of the square of differences between measured and predicted effective thermal conductivities. The predicted effective thermal conductivities were obtained by using various estimates of unknown parameters to calculate $k_{r}$ from Eq. (3), $k_{s}$ from Eq. (4), calculating $k$ according to Eq. (2), and then calculating $k_{e}$ from Eq. (11) using the experimentally measured $T_{H}$ and $T_{B}$ as the integration limits. The results of the parameter estimation are shown in Fig. 5, where the effective thermal conductivity fit at $0.133 \mathrm{~Pa}$, shown as a solid line, is compared with the measured effective thermal conductivities, shown as symbols. The maximum deviation between the fit and measurements was $0.5 \%$. The parameter estimation resulted in $F_{s}=0.167$ and

$$
\frac{e}{n^{* 2}}=6.872-8.795 \times 10^{-3} T+8.484 \times 10^{-5} T^{2}-4.575 \times 10^{-8} T^{3}
$$

The variation of the experimentally estimated $e / n *^{2}$ with temperature for this insulation, shown in Fig. 6, has similar temperature variation as previously published data on silica and alumina fibers, ${ }^{9}$ which are the main constituents of AETB. To evaluate the radiation and solid conduction model, the comparison of measured and predicted effective thermal conductivities as a function of $T_{H}$ at sample densities of 134 and $263 \mathrm{~kg} / \mathrm{m}^{3}$ at $0.133 \mathrm{~Pa}$ pressure is shown in Fig. 7. The rms deviations between measured and predicted effective thermal conductivities were 7.9 and $4.3 \%$ for data at sample densities of 134 and $263 \mathrm{~kg} / \mathrm{m}^{3}$, respectively. These deviations were typically within the experimental uncertainties. The close agreement at lower temperatures for both insulation densities indicates that the solid conduction mode of heat transfer has been modeled satisfactorily. The agreement is not as good at the highest test temperature of $1360 \mathrm{~K}$ : the prediction is slightly below measurement for sample density of $134 \mathrm{~kg} / \mathrm{m}^{3}$, while the prediction is slightly above the measurement (while still within the uncertainty range) for sample density of 263 $\mathrm{kg} / \mathrm{m}^{3}$. The methodology used here assumes that the fiber distribution in the heat flow direction is the same for the samples at different densities, while in reality the fiber distributions may vary slightly for different sample densities, resulting in variations of the radiation component of heat transfer. Despite these discrepancies, the overall close agreement between predictions and measurements at $0.133 \mathrm{~Pa}$ for sample densities of 134 and $263 \mathrm{~kg} / \mathrm{m}^{3}$ based on using parameters estimated from data on a sample with a density of $188 \mathrm{~kg} / \mathrm{m}^{3}$ indicates that the radiation and solid conduction components of heat transfer in this multiplefiber rigid insulation at various densities have been modeled adequately.

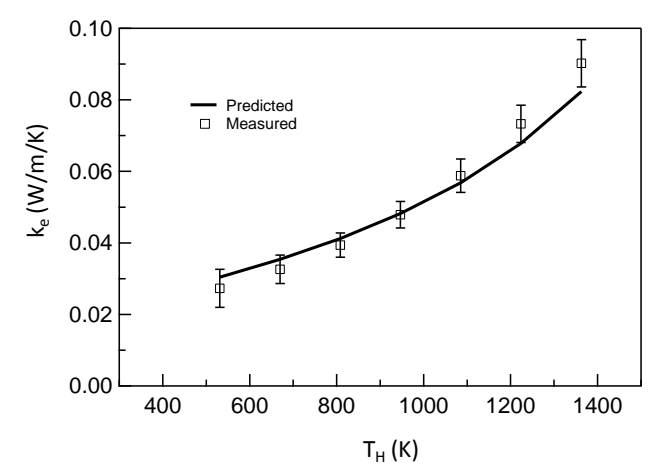

a)

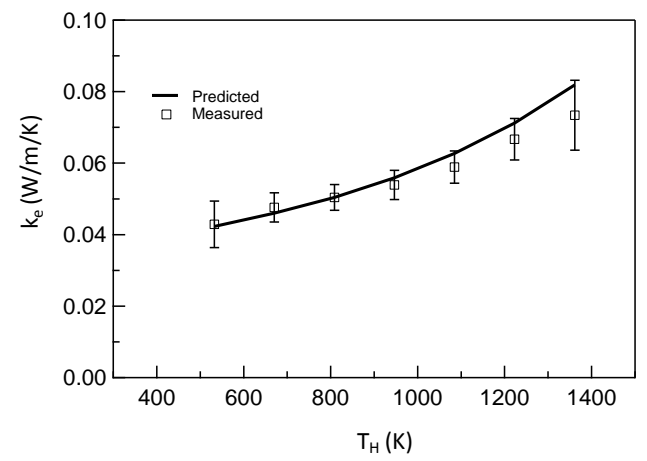

b)

Fig. 7 Comparison of measured and predicted effective thermal conductivity of AETB as a function of $T_{H}$ in a vacuum for sample densities of a) 134 , b) $263 \mathrm{~kg} / \mathrm{m}^{3}$. 


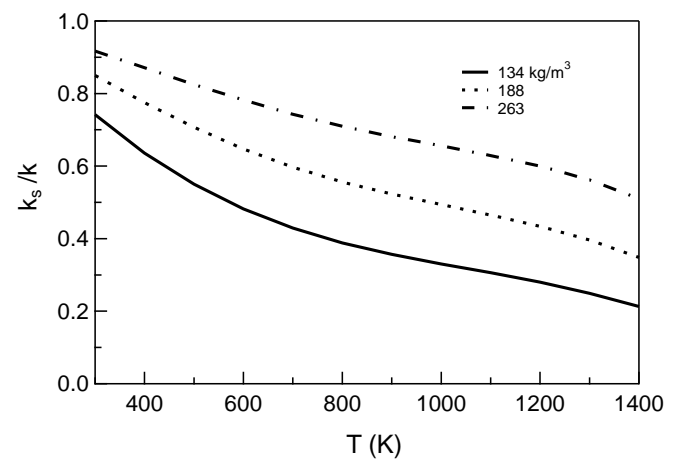

Fig. 8 Variation of predicted ratio of AETB solid thermal conductivity to thermal conductivity (solid conduction and radiation) with temperature in a vacuum at three different sample densities.

With the known relevant parameters for solid conduction and radiation, the relative contributions of these two modes of heat transfer in AETB in a vacuum were studied. The variation of the ratio of solid thermal conductivity to thermal conductivity (solid conduction and radiation) as a function of temperature in a vacuum for the three AETB densities is shown in Fig. 8. As expected solid conduction is the dominant mode of heat transfer at lower temperatures, with 74 to 92 percent of heat transfer at $300 \mathrm{~K}$ being due to solid conduction. The contribution of solid conduction increases with increasing sample density for all temperatures, with the sample at $263 \mathrm{~kg} / \mathrm{m}^{3}$ having the highest ratio of solid conduction to overall heat transfer. Solid conduction component decreases with increasing temperature. The crossover temperature where the ratio of solid conduction to overall heat transfer drops below $50 \%$ varies with insulation density: 600, 1000, and $1400 \mathrm{~K}$ for sample densities of 134,188 , and $263 \mathrm{~kg} / \mathrm{m}^{3}$. It is interesting to note that for various flexible fibrous insulations studied previously solid conduction was not a significant mode of heat transfer, i.e. varying between 9 and $0.1 \%$ between 400 and $1400 \mathrm{~K}$ for an aluminabased flexible fibrous insulation. ${ }^{9}$ Solid conduction plays a significant role in the overall heat transfer in a rigid insulation. The variation of thermal conductivity (solid conduction and radiation) with temperature in a vacuum for the three sample densities is shown in Fig. 9. At lower temperatures $(\mathrm{T}<900 \mathrm{~K})$ thermal conductivity decreases with decreasing density, indicating a solid conduction dominated heat transfer.

At higher temperatures, thermal conductivity generally increases with decreasing density, indicating a radiation dominated heat transfer. The thermal conductivities of samples at densities of 188 and $263 \mathrm{~kg} / \mathrm{m}^{3}$ between 1100 and $1300 \mathrm{~K}$ are almost the same, indicating that the increased solid conduction and decreased radiation due to the higher density for the $263 \mathrm{~kg} / \mathrm{m}^{3}$ sample compared to the $188 \mathrm{~kg} / \mathrm{m}^{3}$ sample somehow negate each other. Above $1300 \mathrm{~K}$, the sample at $188 \mathrm{~kg} / \mathrm{m}^{3}$ has a higher thermal conductivity compared to the sample at $263 \mathrm{~kg} / \mathrm{m}^{3}$, as expected.

With the radiation and solid conduction modes of heat transfer modeled satisfactorily, the gas conduction mode of heat transfer was investigated. The measured effective thermal conductivity data at higher pressures (13.3 to 
$\left.101.3 \times 10^{3} \mathrm{~Pa}\right)$ at various $T_{H}$ in nitrogen gas were used to estimate the effective fiber diameter needed in Eq. (9) for gas conduction modeling. The effective thermal conductivity measurements of samples with densities of 134 and $188 \mathrm{~kg} / \mathrm{m}^{3}$ shown in Fig. 10 were used for this estimation. Average $T_{B}$ for these measurements at all test temperatures and pressures were $339 \pm 16.6 \mathrm{~K}$ and $336 \pm 12.8$ $\mathrm{K}$ for sample densities of 134 and $188 \mathrm{~kg} / \mathrm{m}^{3}$, respectively. The effective fiber diameter for this multi-fiber rigid insulation was estimated to be $1.23 \times 10^{-5} \mathrm{~m}$. The comparison of effective thermal conductivity (including radiation, solid conduction, and gas conduction contributions) fit and measurements as a function of $T_{H}$ for sample densities of 134 and $188 \mathrm{~kg} / \mathrm{m}^{3}$ at 133.3 and 1333.3 Pa pressure are shown in Fig. 10. The overall rms deviation between measurements and predictions for data at all pressures and $T_{H}$ in nitrogen was $11 \%$, indicating a satisfactory fit. The agreement between thermal conductivity fit and measurements is typically better at low and moderate pressures, but the predictions typically underestimate measurements at pressures above $13.3 \times 10^{3} \mathrm{~Pa}$. The same pattern has been noticed previously with flexible fibrous insulations. ${ }^{12,15}$ This discrepancy maybe due to inadequacies in modeling interactions at gas-solid interface, ${ }^{29}$ or other reasons, and is beyond the scope of the present study.

It had been previously postulated that once the characteristic pore size for a fibrous insulation, either flexible or rigid, is known, then the gas conduction model can be used for modeling heat transfer in various gases ${ }^{9}$ simply by using gas properties for various gases in Eqs. $(6-8)$. The main source of uncertainty could be the thermal accommodation coefficient between the various gases and fiber materials. A set of experimental effective thermal conductivity data were generated for AETB sample with a density of $188 \mathrm{~kg} / \mathrm{m}^{3}$ in argon and carbon dioxide gas at various pressures (13.3 to $\left.101.3 \times 10^{3} \mathrm{~Pa}\right)$ and various $T_{H}(500$ to $1360 \mathrm{~K})$ to investigate this hypothesis. For tests in argon, data could only be generated up to $T_{H}$ of $1173 \mathrm{~K}$, because electrical arcing

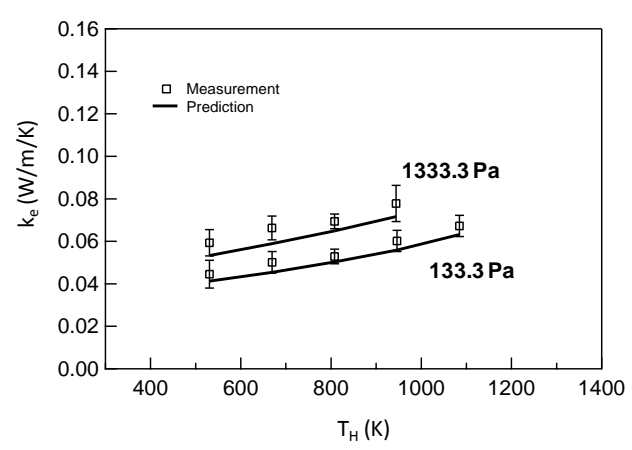

a)

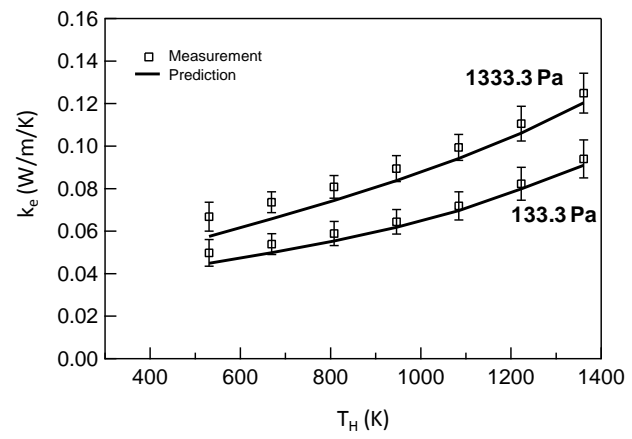

b)

Fig. 11 Comparison of measured and predicted effective thermal conductivity of AETB as a function of $T_{H}$ at various pressures for sample density of $188 \mathrm{~kg} / \mathrm{m}^{3}$ in a) argon, b) carbon dioxide $\left(T_{B}=331.3 \pm 4.2 \mathrm{~K}\right.$ and $337.1 \pm 12.8 \mathrm{~K}$ for tests in argon and carbon dioxide, respectively). occurred in the test setup at higher temperatures and pressures, causing loss of heater power; while testing in carbon dioxide was accomplished without any complications. The variation of experimental effective thermal conductivity data with $T_{H}$ for AETB with sample density of $188 \mathrm{~kg} / \mathrm{m}^{3}$ in argon and carbon dioxide gas at pressures of 133.3 and $1333.3 \mathrm{~Pa}$ is shown in Fig. 11. Average $T_{B}$ for these measurements at all test temperatures and pressures were $331.3 \pm 4.2 \mathrm{~K}$ and $337.1 \pm 12.8 \mathrm{~K}$ for tests in argon and carbon dioxide, respectively. The effective fiber diameter found based on measurements in nitrogen gas was used with argon and carbon dioxide gas properties ${ }^{18-21}$ to calculate the respective contribution of gas conduction, and then calculate predicted effective thermal conductivity. Thermal accommodation coefficient of unity was also used for prediction in these gases. These predictions are shown as solid lines in Fig. 11. The rms differences between measurements and predictions over the entire pressure and temperature range were $11.4 \%$ and $10.4 \%$ for argon and carbon dioxide, respectively, which were similar to the $11 \% \mathrm{rms}$ deviation for fitting of the nitrogen data. The close agreement confirms the hypothesis that once the radiation and solid conduction components of heat transfer and the gas conduction characteristic length are known, overall heat transfer data can be generated in any gas using the model presented here. The gas conduction characteristic length, Eq. (9), can be calculated using either the known mean fiber diameter for single-fiber fibrous insulation, or estimated based on experimental data for multiple-fiber fibrous insulation. The model used in the present study has proved to be satisfactory for modeling heat transfer in both rigid multiple-fiber insulation as well as flexible single-fiber insulation. ${ }^{9}$

Finally, the thermal conductivity predictions for AETB samples at densities of 133 and $194 \mathrm{~kg} / \mathrm{m}^{3}$ were compared with previously reported thermal conductivity measurements ${ }^{6}$ using the radiant step heating method ${ }^{10}$ at various pressures in nitrogen gas for temperatures between 300 and $1100 \mathrm{~K}$. The comparison is shown in Fig. 12 with the experimental data shown as symbols and predictions as solid lines for test pressures of 101.3 and $1013.3 \mathrm{~Pa}$. 
Most of the predictions matched the measurements within the reported $\pm 10 \%$ measurement uncertainty, further validating the heat transfer model developed in the present study. The heat transfer model is applicable over the temperature range of 300 to $1360 \mathrm{~K}$, pressure range of 0.133 to $101.3 \times 10^{3} \mathrm{~Pa}$, and over the insulation density range of 130 to $260 \mathrm{~kg} / \mathrm{m}^{3}$ in various gaseous environments. Extrapolation of data beyond the specified range of parameters could yield erroneous results.

\section{Concluding Remarks}

A combined radiation and conduction heat transfer model was developed for AETB, a multiple-fiber rigid fibrous insulation. The methodology previously developed for thermal modeling of single-fiber flexible fibrous insulation was applied to this multiple-fiber rigid insulation. The relevant radiation and solid conduction parameters were estimated from steady-state thermal test data at various temperatures in a vacuum. The relevant gas conduction parameter was estimated based on measurements at various temperatures and pressures in nitrogen gas. It was shown that the heat transfer model is applicable in various gases and for various sample densities as long as the fiber properties (index of refraction, size distribution, orientation, length) do not change with sample density. This heat transfer modeling methodology can be used with other single or multiple-fiber rigid or flexible fibrous insulation.

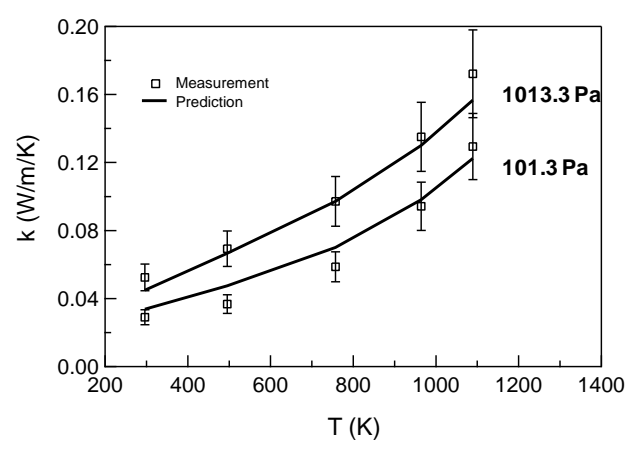

a)

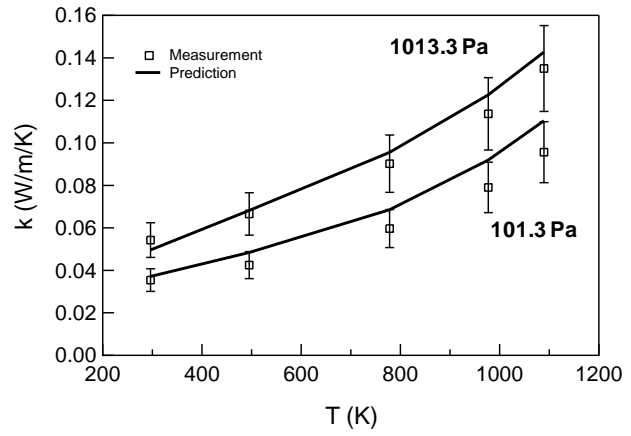

b)

Fig. 12 Comparison of measured and predicted thermal conductivity of AETB as a function of temperature in nitrogen gas at various pressures for sample density of a) 133 , b) $194 \mathrm{~kg} / \mathrm{m}^{3}$.

\section{Acknowledgments}

The authors wish to express their gratitude to the following individuals for their invaluable contributions: Mr. Wayne Geouge, NASA Langley Research Center, for fabrication and instrumentation of steady-state test setup and test samples; Jozef Gembarovic, formerly from TPRL Inc, for providing transient step heating technique thermal conductivity measurements. This work was funded through NASA Fundamental Aeronautics Hypersonic Program. Dr. Max Blosser, NASA Langley Research Center, provided valuable review and guidance.

\section{References}

${ }^{1}$ Roux, J. A., and Smith, A. M., "Combined Conductive and Radiative Heat Transfer in an Absorbing and Scattering Medium," AIChE/ASME Heat Transfer Conference, Paper 77-HT-50, Aug. 1977.

${ }^{2}$ Matthews, L. K., Viskanta, R., and Incropera, F. P., "Combined Conduction and Radiation Heat Transfer in Porous Materials Heated by Intense Solar Radiation,” Journal of Solar Energy Engineering, Vol. 107, No. 1, 1985, pp. 29-34.

${ }^{3}$ Lee, S. C., "Radiative Transfer through a Fibrous Medium: Allowance for Fiber Orientation," Journal of Quantitative Spectroscopy and Radiative Transfer, Vol. 36, No. 3, 1986, pp. 253-263.

${ }^{4}$ Lee, S. C., "Scattering Phase Function for Fibrous Media," International Journal of Heat and Mass Transfer, Vol. 33, No. 10, 1990, pp. 2183-2190.

${ }^{5}$ Lee, S. C., and Cunnington, G. R., "Conduction and Radiation Heat Transfer in High-Porosity Fiber Thermal Insulation," Journal of Thermophysics and Heat Transfer, Vol. 14, No. 2, 2000, pp. 121-136.

${ }^{6}$ Daryabeigi, K., Knutson, J. R., and Cunnington, G. R., "Heat Transfer Measurement and Modeling in Rigid High-Temperature Reusable Surface Insulation Tiles,” AIAA Paper 2011-345, January 2011.

${ }^{7}$ Verschoor, J. D., Greebler, P., and Manville, N. J., "Heat Transfer by Gas Conduction and Radiation in Fibrous Insulations," Transactions of the American Society of Mechanical Engineers, Vol. 74, No. 8, 1952, pp. 961-968.

${ }^{8}$ Kennard, E. H., Kinetic Theory of Gases, McGraw-Hill, New York, 1938, pp. 163-179, 290-318. 
${ }^{9}$ Daryabeigi, K., Cunnington, G. R., and Knutson, J. R., “Combined Heat Transfer in High-Porosity High-Temperature Fibrous Insulation: Theory and Experimental Validation," Journal of Thermophysics and Heat Transfer, Vol. 25, No. 4, 2011, pp. 536546.

${ }^{10}$ Gembarovic, J., and Taylor, R. E, “A Method for Thermal Diffusivity Determination of Thermal Insulators," International Journal of Thermophysics, Vol. 28, No. 6, 2007, pp. 2164-2175.

${ }^{11}$ Stark, C., and Fricke, J., "Improved Heat-Transfer Models for Fibrous Insulations," International Journal of Heat and Mass Transfer, Vol. 36, No. 3, 1993, pp. 617-625.

${ }^{12}$ Daryabeigi, K., "Heat Transfer in High-Temperature Fibrous Insulation," Journal of Thermophysics and Heat Transfer, Vol. 17, No. 1, 2003, pp. 10-20.

${ }^{13}$ Caren, R. P., "Radiation Heat Transfer from a Metal to a Finely Divided Particulate Medium", Journal of Heat Transfer, Vol. 91, 1969, pp. 154-156.

${ }^{14}$ Haupt, R. L., and Haupt, S. E., Practical Genetic Algorithms, Wiley, New York, 1998.

15 Pettyjohn, R. R., "Thermal Conductivity Measurements on a Fibrous Insulation Material," Proceedings of the Seventh Conference on Thermal Conductivity, edited by D. R. Flynn and B. A. Peavy, Jr., U.S. Government Printing Office, NBS Spec. Publ. 302, Washington, DC, 1968, pp 729-736.

${ }^{16}$ Touloukian, Y. S., Powell, R. W., Ho, C. Y., and Klemes, P. G., Thermal Conductivity, Nonmetallic Solids, Vol. 2, Thermophysical Properties of Matter, IFI/Plenum, New York, 1970.

17 Stewart, D. A., and Leiser, D. B., "Characterization of the Thermal Conductivity for Fibrous Refractory Composite Insulations," Proceedings of the 9th Annual Conference on Composites and Advanced Ceramic Materials: Ceramic Engineering and Science Proceedings, Volume 6, Issue 7/8, Wyle, New York, 1985, pp. 769-79.

18 Touloukian, Y. S., Liley, P. E., and Saxena, S. C., Thermal Conductivity, Nonmetallic Liquids and Gases, Vol. 3, Thermophysical Properties of Matter, IFI/Plenum, New York, 1970.

${ }^{19}$ Touloukian, Y. S., and Makita, T., Specific Heat, Nonmetallic Liquids and Gases, Vol. 6, Thermophysical Properties of Matter, IFI/Plenum, New York, 1970.

${ }^{20}$ Touloukian, Y. S., Saxena, S. C., and Hestermans, Viscosity, Vol. 11, Thermophysical Properties of Matter, IFI/Plenum, New York, 1970.

${ }^{21}$ White, F. M., Viscous Fluid Flow, McGraw-Hill, New York, 1974.

${ }^{22}$ Kaganer, M. G., Thermal Insulation in Cryogenic Engineering, Israel Program for Scientific Translations Press, Jerusalem, 1969, pp. 75-76.

${ }^{23}$ Touloukian, Y. S., and Buyco, E. H., Specific Heat, Nonmetallic Solids, Vol. 5, Thermophysical Properties of Matter, IFI/Plenum, New York, 1970.

${ }^{24}$ Goldstein, H. E., Leiser, D. B., Smith, M., and Stewart, D. A., "Opacified Silica Reusable Surface Insulation (RSI) for Thermal Protection of the Space Shuttle Orbiter," Thermal Conductivity, Vol. 15, edited by V. V. Mirkovich, , Plenum Press, New York, NY, 1978, pp. 335-341.

${ }^{25}$ Daryabeigi, K., "Effective Thermal Conductivity of High Temperature Insulations for Reusable Launch Vehicles," NASA TM1999-208972, February 1999.

${ }^{26}$ Daryabeigi, K., Knutson, J. R., and Cunnington, G. R., "Reducing Thermal Contact Resistance for Rigid-Insulation Thermal Measurements," Journal of Thermophysics and Heat Transfer, Vol. 26, No. 1, 2012, pp. 172-175.

${ }^{27}$ Banas, R. P., and Cunnington, G. R., "Determination of Effective Thermal Conductivity for the Space Shuttle Orbiter's Reusable Surface Insulation (RSI)," AIAA Paper 74-730, July 1974.

${ }^{28}$ Coleman, H. W., and Steele, W. G., Experimentation and Uncertainty Analysis for Engineers, Wiley, New York, 1989.

${ }^{29}$ Chumak, I. G., and Pogontsev, V. G., "Heat-Transfer Mechanism at a Gas-Fiber Boundary," Journal of Engineering Physics and Thermophysics, Vol. 36, No. 1, 1979, pp. 37-42. 